\title{
Magic Lantern Glass Slides Materials and Techniques: The First Multi-Analytical Study
}

\author{
Beatriz Rodrigues ${ }^{1}$, Ângela Santos ${ }^{1,2}\left(\mathbb{D}\right.$, Maria J. Melo ${ }^{1,3}(\mathbb{D}$, Vanessa Otero $1,3, * \mathbb{C}$ and \\ Márcia Vilarigues ${ }^{1,2, *}$ \\ 1 Department of Conservation and Restoration, NOVA School of Sciences and Technology (FCT NOVA), \\ 2829-516 Caparica, Portugal \\ 2 Research Unit VICARTE - Glass and Ceramic for the Arts, NOVA School of Sciences and Technology \\ (FCT NOVA), 2829-516 Caparica, Portugal \\ 3 Research Unit LAQV-REQUIMTE, NOVA School of Sciences and Technology (FCT NOVA), \\ 2829-516 Caparica, Portugal \\ * Correspondence: van_otero@campus.fct.unl.pt (V.O.); mgv@fct.unl.pt (M.V.)
}

Received: 31 July 2019; Accepted: 23 August 2019; Published: 29 August 2019

\begin{abstract}
This paper presents the first systematic investigation of hand-painted magic lantern glass slides using multi-analytical techniques combined with a critical analysis of historical written sources of the painting materials and techniques used to produce them. The magic lantern was an optical instrument used from the seventeenth to the twentieth century that attained great success and impact on the entertainment industry, science, religion, and advertisement industry. The glass, colorants, and organic media of five magic lantern slides from the Museum of Natural History and Science of the University of Lisbon were studied. By means of energy-dispersive X-ray fluorescence spectrometry, the glass was characterized and the oxide quantification unveiled that the glass substrate was possibly produced between 1870 and 1930. Ultraviolet-Visible, Raman and Fourier transform infrared spectroscopies allowed the characterization of the colorants: Prussian blue, an anthraquinone red lake pigment of animal origin (such as cochineal), an unidentified organic yellow, and carbon black. The remaining colors were achieved through mixtures of the pure pigments. Infrared analysis detected a complex fingerprint in all colors, nevertheless, a terpenoid resin such as shellac was identified. Metal carboxylates were also detected, contributing to the assessment of the state of conservation of the paints.
\end{abstract}

Keywords: magic lantern slides; material characterization; $19^{\text {th }}$ century glass; $19^{\text {th }}$ century paints

\section{Introduction}

The invention of the magic lantern, which emerged as an instrument of science, took place in the second half of the seventeenth-century and was made possible due to the application of a series of physical principles that allowed for the projection of images. From that moment until the last quarter of the nineteenth-century, it proved to be an optical instrument capable of providing shows that entertained a collective audience by joining the projection of images with the recitation of texts and the interpretation of melodies. This offered entertainment, mystery, and adventure [1,2].

With the projection of images and the synchronized use of sounds, the magic lantern became an audiovisual form with glass as the fundamental support to record the images. This is called a glass slide for a magic lantern.

Magic lantern slides were applied in various contexts and its use has evolved through the centuries. In the eighteenth-century scenes like fables, children's stories, mythological, allegorical, and comical themes were represented in the slides [3]. During the nineteenth century, there was an increase in 
the subjects represented, which then included sequences of popular fiction, topographical themes, historical episodes, news items, educational and pedagogical subjects, as well as ludic scenes, generally combined with movement mechanisms [4,5]. During the transition to the twentieth-century, mainly lithographic and photographic slides were produced, especially for entertainment, pedagogical, and advertisement purposes [3,6].

Research on magic lanterns and historical glass slides has been predominately centered on their role as a precursor to film and cinema. This research provides valuable information on the social, cultural, and economic relationships in the specific context of entertainment and the performing arts and has contributed to an understanding of the history and technical evolution of the apparatus and production processes [7]. Recently, there has been increased awareness that the magic lantern should be perceived as a medium and a cultural phenomenon representing a distinct screen practice [8]. The socio-political contexts in which magic lanterns were used has been a topic of historical media investigations [9]. Initiatives to develop appropriate systems for cataloguing and accessing this information are currently underway (e.g., in the European "A Million Pictures" project). However, despite this interest, no systematic information is currently available on the materials and techniques used in the production of magic lantern glass slides.

To the extent of the authors' knowledge, there are only two papers concerning the characterization of magic lantern slides materials $[10,11]$. One of them studied the presence of gum Arabic, oil, natural resins, and animal glue in different slides by means of attenuated total reflection Fourier transform infrared spectroscopy (ATR-FTIR) and pyrolysis-gas chromatography-mass spectrometry (Py-GC/MS) [10]. The second paper identified oil mixed with watercolor binding and resinous materials using mid-infrared fibre-optic reflectance spectroscopy [11].

The present work, an in-depth analysis of the historical glass and paints used to produce nineteenth-century hand-painted glass slides, combined with a critical analysis of the historical written sources allows, for the first time, to extend our understanding of the artistic context in which historical hand-painted magic lantern glass slides were produced.

\subsection{Historical Sources on Painting Techniques}

Three different techniques were used to manufacture the image on the glass slides for projection by magic lanterns. The first slides produced were hand-painted and this technique gave way to printing techniques in the first half of the nineteenth-century, and in the second half, to photographic techniques, although the last two often included hand-coloring [3].

In order to understand the materials and the painting techniques used for the magic lantern slides, nineteenth-century historical sources were consulted. These written sources are comprised of manuals with practical instructions or edited books on the magic lantern and optical projection instruments. All the historical sources consulted in this study [12-18] indicate that the colors were usually applied from tubes, which could be watercolors or oil colors, following a successive and predefined set of laborious stages that could take several days.

As mentioned in the historical sources consulted, the process began with the selection of the finest thin glass plate, which should have been well cleaned, and the smoother side of the glass was chosen to paint on $[12,13]$. The next step was the drawing of the outline on the glass, which should stay undisturbed through the subsequent painting [12]. Some authors recommended to primarily cover the glass with a thin layer of varnish, diluted gelatin, or a solution of sugar dissolved in water to increase the adhesion of the outline on the glass support. Others recommended using varnish to cover the painted outline to protect it $[14,15]$. The painting process would start by placing the glass in a retouching desk and to use painting procedures and materials similar to the ones used in traditional easel painting; they began by painting the most distant subjects, followed by the foreground, and then finishing the painting [12,15]. After the necessary touch-ups, it was recommended to protect the painting by covering it with a varnish (" [... ] The varnish may be employed at the various stages, 
and at the finish of the work, to fix the colours" [11]) or by placing a similar glass plate on top of the painted one [16].

The major artistic challenge of painting on magic lantern glass slides might be the great mastery necessary for the execution of the drawing and the painting, since once the image is projected, the most minimal details and imperfections are amplified. The other challenge arises from the transparency of the colors. The thickness of the paint layer and the amount of pigment used had a strong influence on the final result [3], and if the paint was not transparent enough, it would not be possible to project the image. To achieve transparency, the colors used to paint the magic lantern slides were necessarily less varied than the ones for traditional painting, and the authors of the written sources of the nineteenth-century were aware of that $[12,17,18]$.

Specific colors and materials by Winsor and Newton (one of the most relevant artists' colourmen of the nineteenth-century) for painting on glass are mentioned for the first time in their catalogue from 1863. This catalogue also lists the fourth edition of the book The Art of Transparent Painting on Glass, a manual on the "method of painting, and an account of the implements and materials employed in producing subjects for dissolving views, magic lanterns [ ... ] for obtaining effects of motion and color" [12]. According to its author, Edward Groom, the colors used for painting on glass were those "prepared for watercolor painting, and procurable in tubes" as they were "transparent, that is, through which light is transmitted". The colors described by Groom are Gamboge, Italian Pink, Gallstone, Indian Yellow, Madder Lake, Crimson Lake, Prussian Blue, Indigo, Burnt Sienna, Madder Brown, Vandyke Brown, and Lamp Black [12].

Painting on magic lantern glass slides required the mastery of miniature painting on a glass substrate, and therefore, hand-painted glass slides are considered to be miniature masterpieces of cold paint on glass in their own right [3].

\subsection{Case Study}

This paper details the first systematic and multi-analytical study of the materials and techniques employed in hand-painted magic lantern slides from Portuguese museum collections. This work focuses on the material characterization of five hand-painted slides from the Museum of Natural History and Science of the University of Lisbon (MUHNAC-ULisboa). Figure 1 illustrates one of the five magic lantern slides currently being studied. The other four are displayed in the Appendix A (Figures A1-A4).

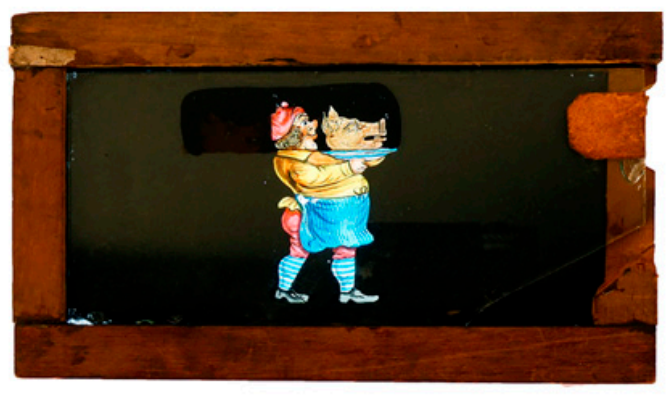

(A)

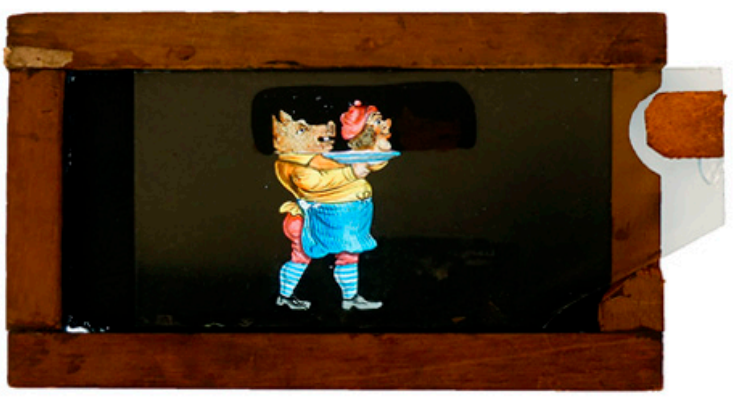

(B)

Figure 1. Hand-painted single slipping glass slide with inventory number MUL/MUHNAC UL000068 from MUHNAC-ULisboa; each slide has a dimension of approximately $175 \times 101 \mathrm{~mm}$ and they represent: (A) still image and (B) movable image when the slipping glass is operated.

The slides are denominated in single slipping slides [19] since one glass is stationary (mounted glass), secured to the wood frame with metal nails, and the other glass is, to an extent, movable 
(slipping glass). The movement of the slipping glass allows for the idea of animation intended with this type of slide.

The mounted glass has an opaque black background and contains most of the drawing, namely, the subjects that still remain. The slipping glass on top, which appears slightly separated from the other glass by some paper tape painted black, is the one to be pulled in and out to achieve the movement action. This glass is painted with the part of the drawing that intends to "move" when handled; the orange tape serves the purpose of pulling the glass.

Under the stereomicroscope, it is noticeable that the black outline was drawn first, and the colors were applied on top. A shiny resinous-like appearance is seen over the colors, which is in opposition to the opaque black background that surrounds the subjects. This could imply the presence of a varnish or a resin-like material. It is quite interesting to notice that the white color is achieved by the absence of paint, which allows the light to pass through entirely.

Besides careful brushstrokes of the black outline, brushstrokes of a slightly darker hue of one color are visible, giving the idea of a shadow or darker area (Figure 2B), which adds detail. The intensity of the brushstroke is also varied according to the desired effect of lighter or darker details. Equally interesting is another technique observed that is similar to stained glass, namely in grisaille, which is a technique of "opening lights" in which the black background seems to be scraped off to reveal another color beneath (Figure 2A). This seems to demonstrate that the outline was made simultaneously with the black background and that creative techniques and materials were employed to achieve several effects, as well as the juxtaposition of colors being used to create more intricate patterns (Figure 2B).

Regarding the provenance of these objects, it is plausible to suggest that they could have been produced in the nineteenth-century in England, especially when considering the 'standardized size' of the slide, the similarity of the subject represented [19], and the 'wide production' of similar depictions, with slight color and stylistic differences that can be found in several collections attributed to this period and place of production. This suggestion is in agreement with the information presented in MUHNAC's inventory that points to the nineteenth century as the date range for the execution of these magic lantern slides.

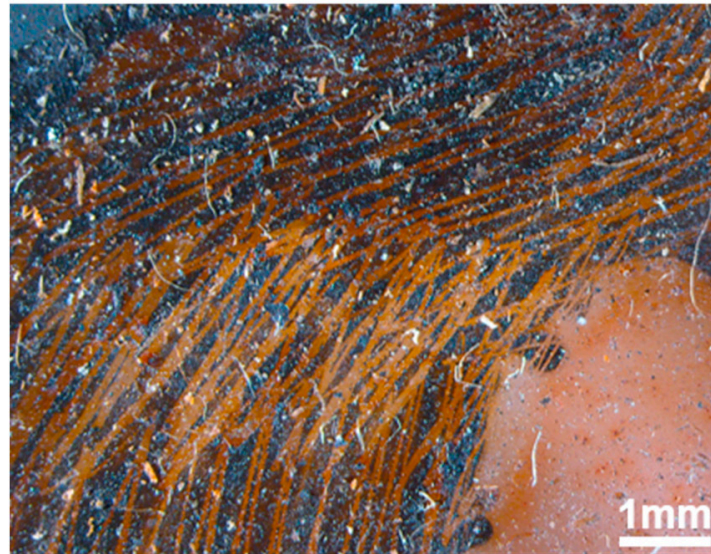

(A)

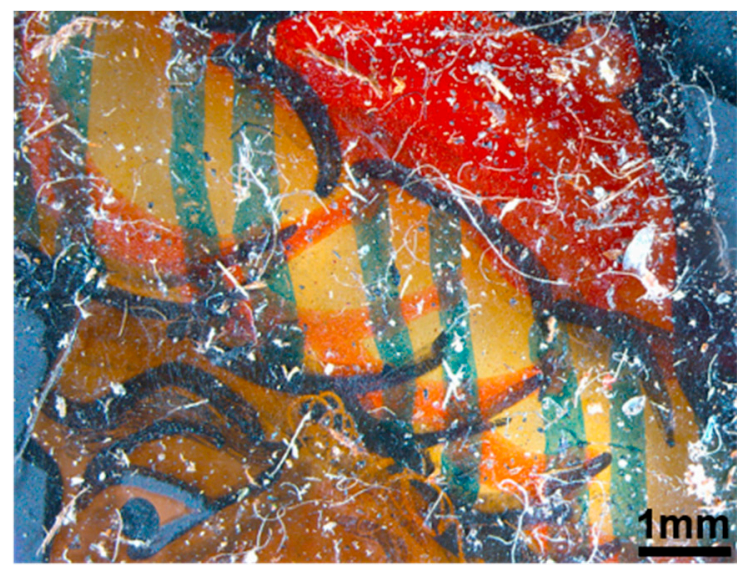

(B)

Figure 2. Detail (stereomicroscope photography) of (A) the black background scraped off to reveal the brown color underneath, giving a more realistic effect to the hair (slide MUL/MUHNAC UL000065) and (B) the juxtaposition of blue, red, and yellow colors, creating more intricate patterns (slide MUL/MUHNAC UL000067). Note that the white particulate observed at the surface corresponds to the dirt seen under the light.

\section{Materials and Methods}

One of the main goals of this work was the development of a multi-analytical experimental methodology for the material characterization of the hand-painted glass slides, namely for the 
identification of the glass support, the colorants, and organic media, using analytical techniques that are complementary to each other. The glass was characterized using micro-energy dispersive X-ray fluorescence spectrometry ( $\mu$-EDXRF) and the identification of the painting materials was performed by Ultraviolet-Visible absorption spectroscopy (UV-Vis), micro-Raman spectroscopy ( $\mu$-Raman), and Fourier transform infrared spectroscopy ( $\mu$-FTIR). Whenever possible, in situ analyses were performed in three different areas of the same color and micro-sampling was only employed for $\mu$-FTIR analyses. Figures A5-A8 in the Appendix A display the areas of micro-sampling and of the in situ analyses presented in this work.

\subsection{Stereomicroscope}

Examination and detailed photography of the slides were carried out under a Leica MZ16 stereomicroscope $(7.1 \times$ to $115 \times$ zoom range), equipped with a Leica ICD digital camera, and a fiber-optic light Leica system (Leica KI 1500 LCD).

Micro-sampling was also performed under the stereomicroscope using a micro-chisel from Ted Pella microtools.

\subsection{Micro-Energy Dispersive X-Ray Fluorescence Spectrometry (EDXRF)}

The analyses were carried out using an ARTAX 800 spectrometer, equipped with an air-cooled low-power X-ray tube with a Mo target and $X$ flash ${ }^{\circledR}$ Peltier cooled silicon drift detector. The primary $\mathrm{X}$-ray beam is focused to a diameter of 70 micrometers by means of a polycapillary $\mathrm{X}$-ray mini lens. The spectrometer was operated at $40 \mathrm{kV}, 0.6 \mathrm{~mA}$, and $360 \mathrm{~s}$ acquisition time in a He atmosphere. At least three different measurements were made in each glass (mounted and slipping glass).

Quantitative analyses were carried out with the WinAXIL program, making use of spectra obtained from A, B, C, and D reference glass composition standards from Corning Museum of Glass (CMoG), Corning, NY, USA [20]. The analytical capability of the equipment is limited to elements with an atomic number $Z \geq 13$, thus making detection of sodium and magnesium impossible. The concentration of these elements was calculated by the 'matrix by difference', which does not allow for the separation of either of these elements from other light elements that may also exist in the glass. This method is less rigorous because it is not possible to separate both elements from other light elements that may also exist in the glass composition.

The error associated with the analysis was calculated for $\mathrm{SiO}, \mathrm{K}_{2} \mathrm{O}, \mathrm{CaO}, \mathrm{Fe}_{2} \mathrm{O}_{3}, \mathrm{SrO}$, and $\mathrm{SnO}_{2}$ below $5 \%$. The calculated error for $\mathrm{MnO}, \mathrm{Al}_{2} \mathrm{O}_{3}, \mathrm{ZnO}, \mathrm{CoO}$, and $\mathrm{CuO}$ was below $10 \%$. For the remaining oxides, the error was below $25 \%$, which was verified by analyzing standard glasses (CMoG $\mathrm{B}$ and $\mathrm{D}$ ) under the same experimental conditions as the samples and experimentally calculating the concentration values of the certified samples. $\mathrm{P}_{2} \mathrm{O}_{5}$ and other standard deviations of light elements calculated by the same method were much higher, and therefore, this is considered to be a semi-quantitative method.

The single slipping slides were dismounted by temporarily removing the metal nails that keep the slipping glass in place in order to allow for the in situ analysis on both sides (A and B), on both glasses (mounted and slipping glass), and on each slide. No detectable differences between the two sides of all glasses were found, allowing us to assume that none of the glasses were produced with the float glass method and no relevant alkali leaching, associated with the corrosion process of the glass, has occurred.

\subsection{UV-Vis Spectroscopy (UV-Vis)}

UV-Vis spectra were acquired in absorbance mode using an AvaSpec-2048-SPU spectrophotometer with an AvaLight-HAL Tungsten Halogen as a light source (Avantes). The AvaSoft software controlled the acquisition of the spectra in the 200-1100 $\mathrm{nm}$ range. In situ measurements were performed using a $20 \mathrm{~ms}$ integration time and with 50 accumulations. 


\subsection{Micro-Raman Spectroscopy ( $\mu$-Raman)}

The analyses were carried out in situ using a Labram 300 Jobin Yvon spectrometer, equipped with a HeNe laser $17 \mathrm{~mW}$ operating at $632.8 \mathrm{~nm}$. Spectra were recorded as an extended scan. The laser beam was focused with $50 \times$ and $100 \times$ Olympus objective lens. The laser power at the surface of the samples was varied with the aid of a set of neutral density filters (optical densities $0.3,0.6$, and 1 ). The spectra were acquired using $10 \mathrm{~s}$ laser exposure time for 5 scans.

\subsection{Micro-Fourier Transform Infrared Spectroscopy ( $\mu$-FTIR)}

Infrared spectra were acquired with a thermo-nicolet nexus spectrophotometer coupled to a Continu $\mu \mathrm{m}$ microscope $(15 \times$ objective) with a MCT-A detector cooled by liquid nitrogen. Spectra were obtained in transmission mode between 4000 and $650 \mathrm{~cm}^{-1}$, with a resolution of $8 \mathrm{~cm}^{-1}$, and 128 scans, and with a spot size of $50 \times 50$ microns. Samples were previously compressed using a thermo diamond anvil compression cell. Spectra are shown here as acquired, without corrections or any further manipulations, except for the occasional removal of the $\mathrm{CO}_{2}$ absorption at $\sim 2300-2400 \mathrm{~cm}^{-1}$.

\section{Results and Discussion}

\subsection{Characterization of the Glass}

Through glass characterization, the quantification of its composition in oxides, and the comparison with reference studies in the field of English flat glass from the nineteenth to early twentieth-century, it was possible to infer the production date of the magic lantern slides.

The analyzed samples belong to the soda-lime silicate glass type, containing $\mathrm{SiO}_{2}$ from $73 \mathrm{wt} \%$ to $75 \mathrm{wt} \%, \mathrm{~K}_{2} \mathrm{O}$ circa $0.2 \mathrm{wt} \%, \mathrm{Na}_{2} \mathrm{O}+\mathrm{MgO}$ from 6.5 to $9.5 \mathrm{wt} \%$, and $\mathrm{CaO}$ from 13 to $15.5 \mathrm{wt} \%$. The concentration of $\mathrm{Al}_{2} \mathrm{O}_{3}$ lays between $2.6 \mathrm{wt} \%$ and $1.3 \mathrm{wt} \%, \mathrm{Fe}_{2} \mathrm{O}_{3}$ varies between $0.15-0.3 \mathrm{wt} \%$, and $\mathrm{MnO}$ content is inferior to $700 \mathrm{ppm}$. Other relevant oxides are $\mathrm{As}_{2} \mathrm{O}_{3}(\sim 0.05 \mathrm{wt} \%), \mathrm{SrO}(0.02 \mathrm{wt} \%)$, $\mathrm{SnO}_{2}\left(0.04-0.07 \mathrm{wt} \%, \mathrm{ZnO}(<900 \mathrm{ppm})\right.$, and $\mathrm{TiO}_{2}(\sim 0.04 \mathrm{wt} \%)$.

Considering the probable production place (England) of the painted glass slides studied, the obtained glass compositions were compared with the study by Dungworth [21] on historical window glass. As mentioned, the glass used for the production of the slides is of the soda-lime silicate type, produced with synthetic soda, and the results suggest that it is dated between 1870 and 1930, due to the low arsenic oxide content $(<0.2 \mathrm{wt} \%)$ and potassium oxide content of circa $0.2 \mathrm{wt} \%$. Further analysis to establish the precise $\mathrm{MgO}$ content is needed to confirm this dating.

While the production date range of the glass substrate extends into the twentieth-century, it is possible to narrow the production range of this collection between 1870 and 1900, considering the 'standardized size' of the slides and the similarity of the subject represented with other magic lantern slides entirely produced in England.

\subsection{Identification of the Color Palette}

The color palette of the studied magic lantern slides is consistent with the written sources of the nineteenth-century, especially the Groom's manual [12]. It is composed of the primary colors obtained through pure pigments, including Prussian blue, an anthraquinone red lake of animal origin (such as cochineal), and an unidentified organic yellow pigment. The black color was obtained by carbon black. The remaining colors were achieved through mixtures. Therefore, this means that, overall, blue, red, yellow, and black were applied as pure pigments, while green, orange, and brown were the result of mixtures from primary colors (Figure 3).

Specifically regarding the green color, it is in accordance with the information of the nineteenth-century written sources on how to paint transparencies on glass for magic lanterns [12-18], since there are no green pigments listed, which suggests that this color was indeed achieved by mixing yellow and blue. 
Figure 3 also shows the level of detail put into the painting process, with some noticeably careful brushstrokes, whose brilliance is evident despite the presence of a substantial amount of superficial dirt.

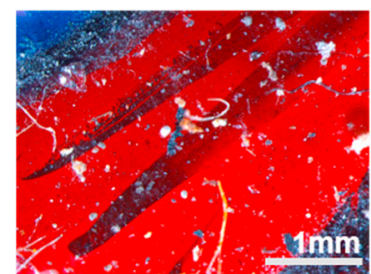

Anthraquinone red lake

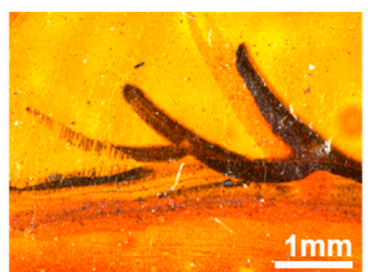

Organic yellow

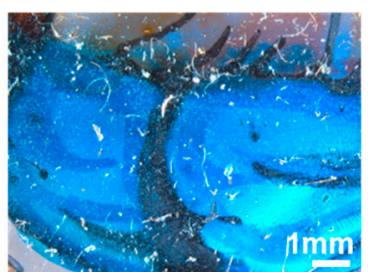

Prussian blue

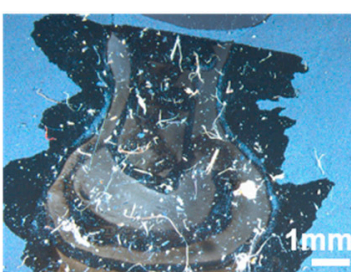

Carbon black

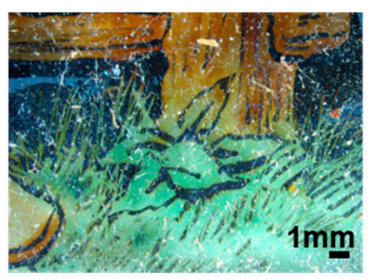

Green: yellow + blue

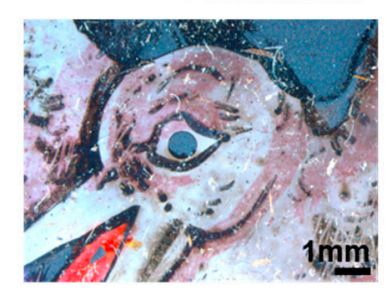

Purple: red + blue

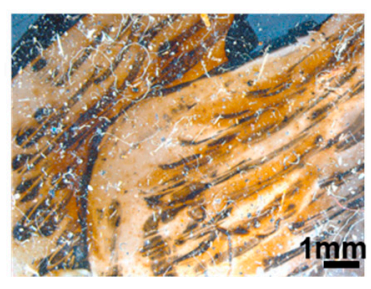

Brown: yellow + blue + red

Figure 3. Details of the colors found in the hand-painted magic lantern slides studied (stereomicroscope photography). The identification of the colorants is fully discussed below, which is supported by the corresponding spectra. Starting from the top to the bottom, from left to right, the photos correspond to the slides MUL/MUHNAC UL000067, MUL/MUHNAC UL000068, MUL/MUHNAC UL000066, MUL/MUHNAC UL000066, MUL/MUHNAC UL000066, MUL/MUHNAC UL000066, and MUL/MUHNAC UL000069. Note that the white particulate observed at the surface corresponds to the dirt seen under the light.

\subsubsection{Blue Color}

The UV-Vis absorption spectrum of the blue color, Figure $4 \mathrm{~A}$, shows an absorption band that is characteristic of the charge transfer transition between the $\mathrm{Fe}^{2+}$ and $\mathrm{Fe}^{3+}$ ions between $600-1000 \mathrm{~nm}$ $[22,23]$.

The $\mu$-Raman spectrum allowed the clear identification of the Prussian blue pigment, Figure $4 \mathrm{~B}$, displaying the characteristic stretching vibrations of the triple $\mathrm{CN}$ bond at $2070-2200 \mathrm{~cm}^{-1}$ [24], which is visible in the spectrum at $2152 \mathrm{~cm}^{-1}$ and $2090 \mathrm{~cm}^{-1}$. Bands located in the spectral window between $450-620 \mathrm{~cm}^{-1}$ are characteristic of all Fe-C stretching vibrations [24] and manifest in the spectrum at $523 \mathrm{~cm}^{-1}$. The lower spectral region (190-340 $\mathrm{cm}^{-1}$ ) with bands at $277 \mathrm{~cm}^{-1}$ and $328 \mathrm{~cm}^{-1}$ concern the Fe-CN-Fe bond deformation vibrations [24].
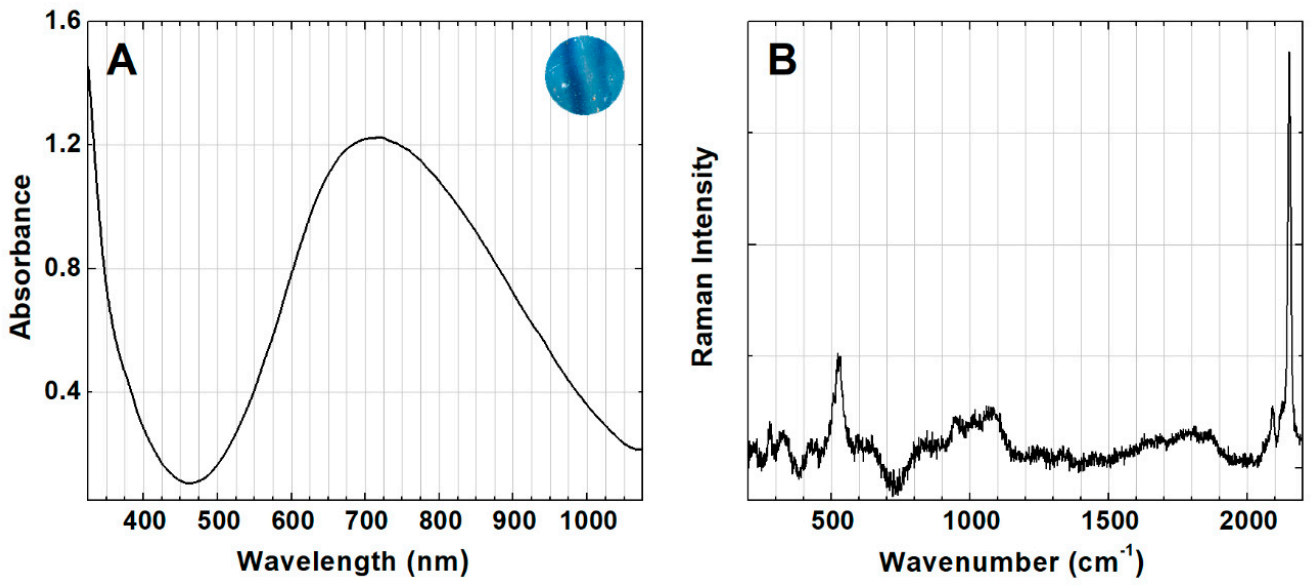

Figure 4. (A) UV-Vis and (B) Raman spectra of the blue color identified as Prussian blue. 


\subsubsection{Red Color}

The UV-Vis spectra representative of the red color in all glass slides is presented in Figure 5A. This shows an absorption band structured into two characteristic bands at $522 \mathrm{~nm}$ and $562 \mathrm{~nm}$, indicating the presence of an anthraquinone red chromophore of animal origin (such as kermes, lac, and cochineal) identifiable by the shifting of the band to lower wavelengths. These bands are related to the conjugated double bonds of the anthraquinone molecule, assigned to $n \rightarrow \pi^{*}$ transitions of the carbonyl groups $[25,26]$.

Figure $5 \mathrm{~B}$ shows the infrared spectrum of the red color where it is possible to identify gypsum $\left(\mathrm{CaSO}_{4} \cdot 2 \mathrm{H}_{2} \mathrm{O}\right)$ through its characteristic bands at $3405 \mathrm{~cm}^{-1}(\mathrm{OH}$ stretching $), 1621 \mathrm{~cm}^{-1}\left(\mathrm{H}_{2} \mathrm{O}\right.$ bending $)$ $1125 \mathrm{~cm}^{-1}\left(\mathrm{SO}_{4}{ }^{2-}\right.$ asymmetric stretching), and $669 \mathrm{~cm}^{-1}\left(\mathrm{SO}_{4}{ }^{2-}\right.$ asymmetric bending). Its presence is in agreement with the EDXRF analyses, which always detected a higher quantity of calcium, together with sulfur, in the red areas of the glass slides. The presence of a terpenoid resin, such as shellac, was also identified, and it is further discussed in Section 3.3. More importantly, the infrared spectrum compares very well with that of an historical W\&N Crimson Lake oil paint tube, which has been characterized as a cochineal red lake paint where gypsum was added during pigment manufacture [27]. Investigation into the W\&N nineteenth-century manufacturing processes for cochineal lake pigments $[27,28]$ has enabled the identification of the main infrared bands attributed to the W\&N Crimson lake pigment, in the form of a complex of carminic acid with aluminum and calcium, namely at 1569, 1465, 1411, 1309, 1288, and $1250 \mathrm{~cm}^{-1}$ [28], which are also observed in Figure 5B.

As previously noted, the use of Crimson Lake for painting on glass was recommended by Groom [12]. The complementary results obtained strongly suggest that the red color is given by a cochineal red lake pigment, however, to confirm the presence of the carminic acid, further analyses by surface enhanced Raman spectroscopy (SERS) or high-performance liquid chromatography-diode array detector (HPLC-DAD) will be necessary.
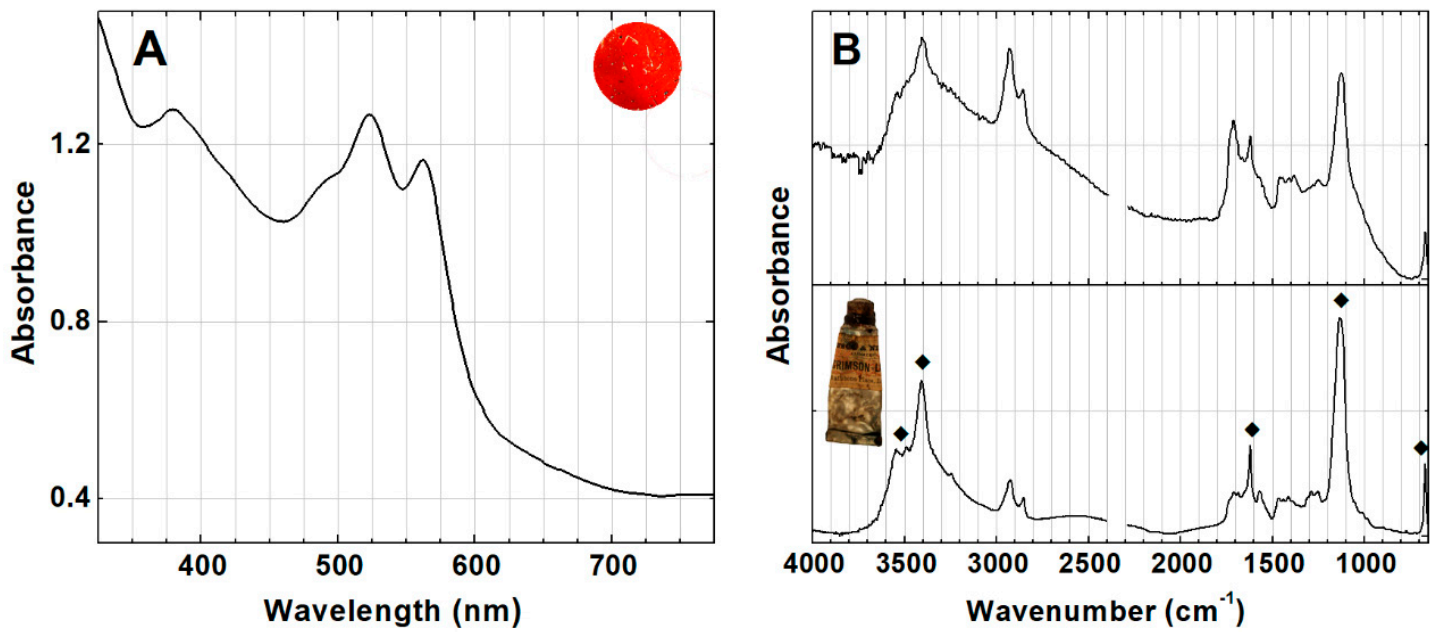

Figure 5. (A) UV-Vis spectrum of the red color and (B) Infrared spectra of the red color (top) and of a $19^{\text {th }}$ century W\&N Crimson oil paint (bottom). These spectra strongly suggest that the colorant present is a cochineal red lake pigment. ( $\bullet$ gypsum $\left(\mathrm{CaSO}_{4} \cdot 2 \mathrm{H}_{2} \mathrm{O}\right)$.

\subsubsection{Yellow Color}

Despite the use of complementary analytical techniques, it was not possible to identify the yellow colorant. Nevertheless, the absence of a Raman signal and the similarities between the EDXRF spectra of the glass and the yellow paint indicate the use of an organic colorant. The representative UV-Vis spectrum may be consulted in the Appendix A (Figure A9). The infrared analysis was consistent with the previous techniques and only revealed the presence of degradation products associated with the 
organic media used, as discussed in Section 3.3. Future work will be carried out in order to fully identify the nature of the yellow color.

\subsubsection{Black Color}

The $\mu$-Raman spectrum of the black color is shown in Figure 6, displaying two characteristic bands situated at 1336 and $1585 \mathrm{~cm}^{-1}$. The shape of the $\mu$-Raman spectrum and position of the characteristic bands, generally at c. $1580 \mathrm{~cm}^{-1}$ and c. $1350 \mathrm{~cm}^{-1}$, indicates the presence of a carbon black pigment $[29,30]$. The absence of a band at $950 \mathrm{~cm}^{-1}$ [30] can dismiss the possibility of the use of ivory black, but to understand if, for example, a lamp black pigment was used, as mentioned by Groom, more analyses will be needed. The $\mu$-EDXRF analysis did not reveal the presence of phosphorus, which corroborates this conclusion. The spectra of the black color analyzed was very similar to the spectra of the glass reinforcing the organic nature of the pigment.

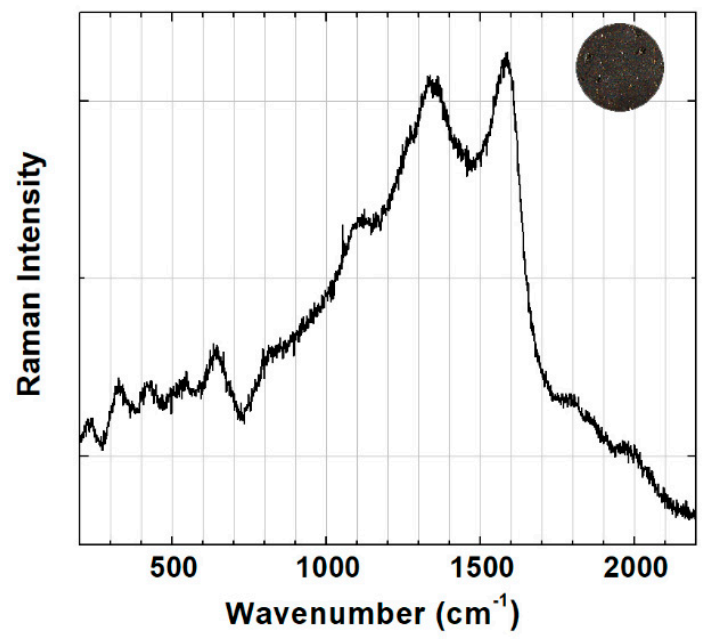

Figure 6. Raman spectrum of the black color identified as carbon black.

\subsubsection{Mixed Colors: Green, Purple and Brown}

As expected, due to the absence of references to green pigments in historical written sources from the nineteenth-century, the green color analyzed appears to be a mixture of yellow and blue. This suggestion is corroborated by the UV-Vis spectrum (Figure 7A) through the existence of a broad band at $600-1000 \mathrm{~nm}$ (with maximum absorption at $690 \mathrm{~nm}$ ), which is characteristic of Prussian blue, and by the presence of the band at $380 \mathrm{~nm}$, which corresponds to the yellow pigment (UV-Vis spectrum displayed in Figure A9 in the Appendix A).

The infrared spectrum of the purple color (note that this color is exclusively present in the slide MUL/MUHNAC UL000066) reveals that it is a mixture of red and blue, as the spectrum displayed in Figure $7 \mathrm{~B}$ is very similar to the infrared spectra of the red (Figure $5 \mathrm{~B}$ ) with the addition of a band at $2090 \mathrm{~cm}^{-1}$, which is characteristic of Prussian blue [31]. 

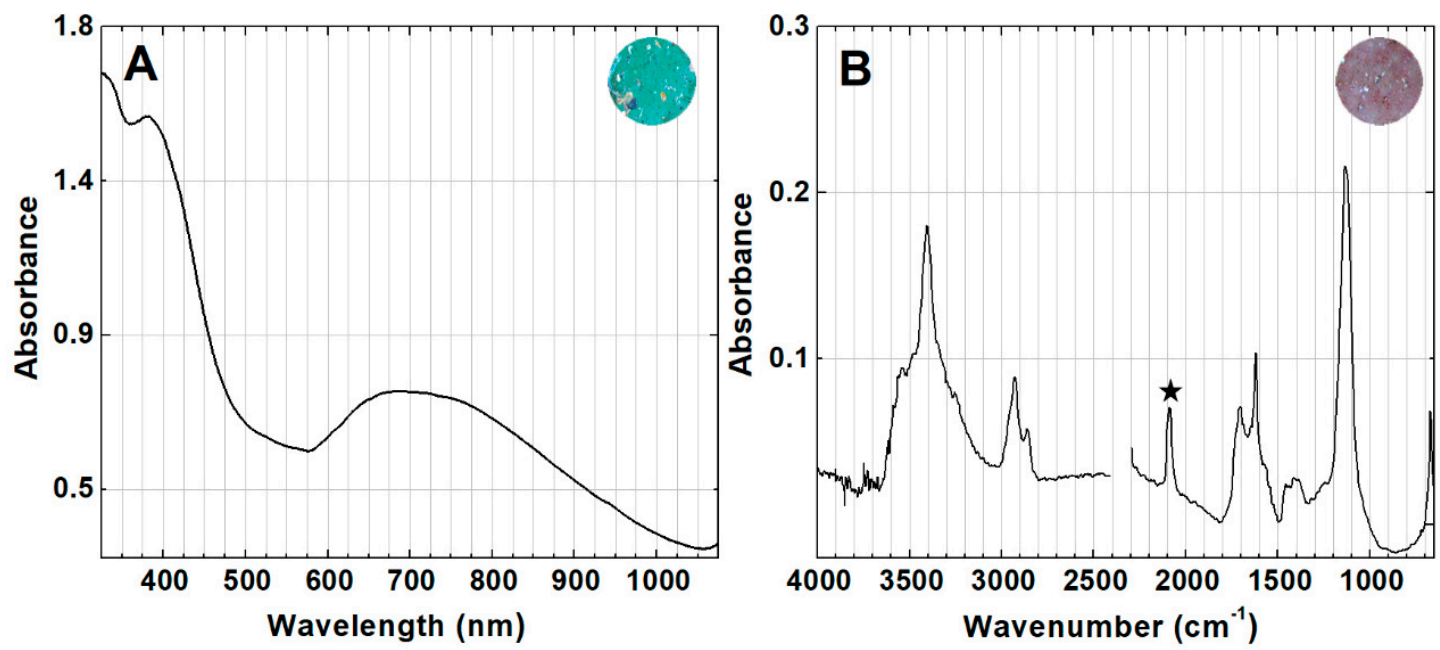

Figure 7. (A) UV-Vis spectrum of the green color, a mixture of the organic yellow and Prussian blue; and (B) Infrared spectrum of the purple color, a mixture of the red and Prussian blue ( $\star$ ).

Despite the suggestions of some nineteenth-century authors on how to paint transparencies on the magic lantern slides, such as Groom [12], regarding the use of ochres or earth pigments to paint the brown areas, all the brown hues analyzed revealed to be a mixture of the primary colors (blue + yellow + red). It could be suggested that the oil paint tube used already had this mixture, but an extensive study on ochre samples from nineteenth-century oil paint tubes proved that pure ochre brown pigments were available on the market [32]. It is likely that these would not allow obtaining the desired transparency and the artists found other solutions to achieve more transparent and brighter brown shades.

\subsection{Identification of the Organic Media and Its State of Conservation}

The infrared analyses revealed a complex fingerprint in all colors, as may be seen in Figure 5B, Figure 7B, and Figure 8. Analyses performed on a drop of a transparent resinous material found at the surface of a slide (MUL/MUHNAC UL000067; Figure A3), as well as in a varnish found in its colorless area, enabled the identification of a terpenoid resin such as shellac. Their infrared spectra displayed a $\mathrm{CH}$ stretching profile with bands at 2930 and $2856 \mathrm{~cm}^{-1}$, a broad $\mathrm{C}=\mathrm{O}$ stretching band centered at $1716 \mathrm{~cm}^{-1}$, an NH bending/CC stretching band at $1637 \mathrm{~cm}^{-1}$, and C-O stretching bands of carboxylic acids at 1253 and $1040 \mathrm{~cm}^{-1}$ (Figure 8B) [33,34]. However, the presence of other binding media cannot be excluded, and further analyses, such as pyrolysis-gas chromatography/ mass spectrometry (Py-GC/MS), must be carried out in order to fully characterize the organic media present and their role in the painting process [35].

Shellac is a natural resin derived from the resinous secretion of the lac insect (Laccifer lacca) that has a very complex composition with mixtures of different mono and polyesters of hydroxyaliphatic and sesquiterpenoid acids [35]. During the nineteenth century, methods for decolorizing shellac resin, such as chemical bleaching, were developed and one of the resulting products was commonly known as white lac varnish [36]. This varnish was recommended by many nineteenth-century authorities on painters' materials, due to its transparency, hardness, and durability [37]. Interestingly, there is also a reference to its use in Groom's manual: "[ ... ] having perfected the outline, we secure it by passing over the face of the glass a thin wash of lac varnish [ ... ]. The varnish may be employed at the various stages, and at the finish of the work, to fix the colors." [12]. 

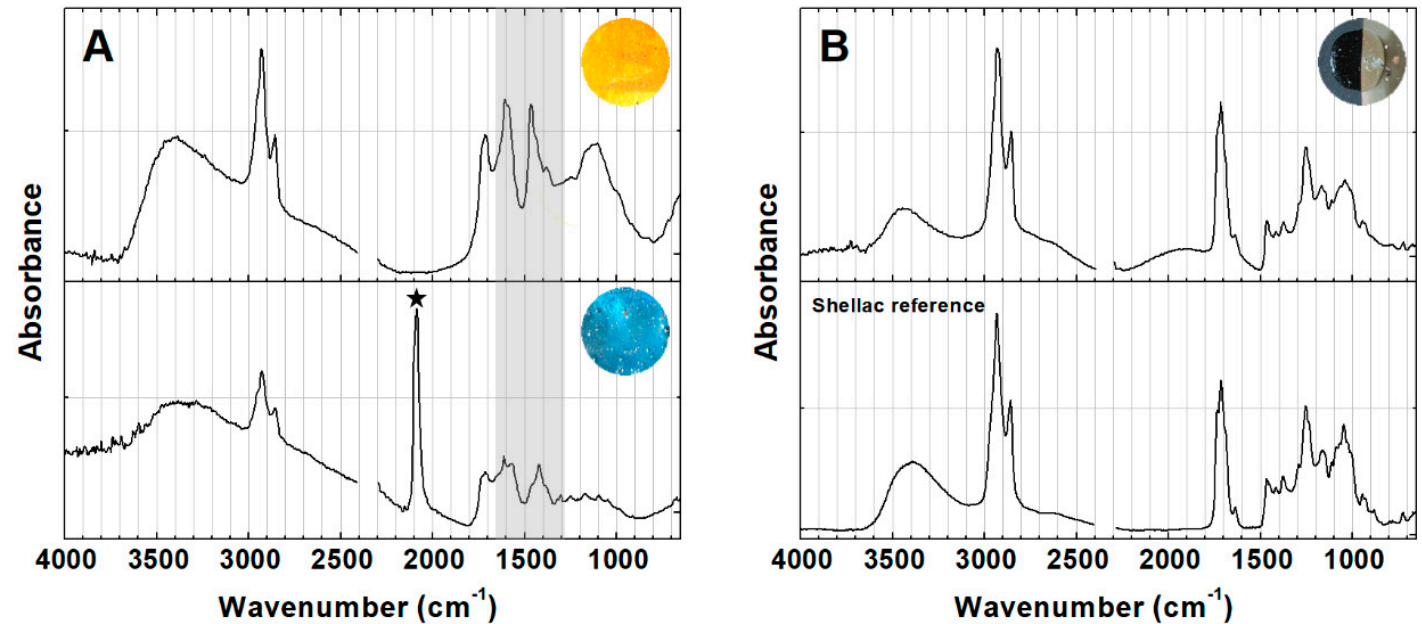

Figure 8. Infrared spectra of (A) the yellow and blue ( $\star$ Prussian blue) colors, where the region of degradation products such as carboxylates and oxalates is highlighted; and (B) the transparent resinous material found at the surface of the slide (MUL/MUHNAC UL000067) compared to a reference of shellac (Kremer).

Figure 8A presents the infrared spectra of the yellow and blue colors, where the $\mathrm{COO}^{-}$stretching absorption region of metal carboxylates is highlighted. The first shows two strong, broad bands centered at $1605 \mathrm{~cm}^{-1}$ and $1464 \mathrm{~cm}^{-1}$ that may be assigned to $\mathrm{COO}^{-}$stretching and $\mathrm{CH}_{2}$ bending vibrations of metal carboxylates, respectively [38]. The second also displays bands at 1570 and $1420 \mathrm{~cm}^{-1}$, attributable to metal carboxylates, in addition to bands at 1612,1323 , and $1304 \mathrm{~cm}^{-1}$, which may be assigned to $\mathrm{COO}^{-}$stretching vibrations of metal oxalates [39]. Unfortunately, the clear identification of the type of carboxylate and oxalate was not possible. In this case, it must be taken into consideration that different terpenoid acids may be part of the carboxylate structures [40-42].

It is noteworthy that, although the infrared spectra show signs of degradation products, no conservation problems are macroscopically visible. This is most likely because the slides were kept inside of a box, in the dark, and with no significant changes of relative humidity and temperature, at MUHNAC, for many years, which likely prevented photochemical reactions. Therefore, it is suggested that the slides should be kept in similar conditions, protected from light, and with no fluctuations of environmental conditions.

\section{Conclusions}

The magic lantern was an instrument for image projection with a high cultural, historical, and social impact between the seventeenth and nineteenth-centuries, marking the "pre-cinema period". During the nineteenth-century, several books with instructions on how to paint transparencies on glass for magic lanterns were published. These essential sources were consulted and provided us insights on which painting materials and techniques can be expected to be found on historical magic lantern slides.

In this work, five hand-painted magic lantern glass slides from the Museum of Natural History and Science of the University of Lisbon were studied and characterized by complementary techniques. The glass substrate was characterized via EDXRF and then quantified in oxide weight percentage. The comparison of the results obtained from English flat window glass studies allows the suggestion that the glass was produced in the period between 1870 and 1930, due to the low content of arsenic $(<0.2 \mathrm{wt} \%)$ and the similarity of the general composition with that of window glass from that period. It is possible to narrow the production range of this collection between 1870 and 1900, considering the 'standardized size' of the slides and the similarity of the subject represented with other English magic lantern slides. Through spectroscopic techniques, it was possible to identify the following colorants: Prussian blue, an anthraquinone red lake pigment of animal origin (such as cochineal), and carbon black. The yellow was obtained from an organic colorant whose identification was not yet possible. 
These results are in agreement with The Art of Transparent Painting on Glass, written by Edward Groom (1855), and other historical sources. The remaining colors were found to be achieved through mixtures of the primary ones. This was expected for the green, since none of the nineteenth-century sources mentioned a green pigment, which suggests that this color was obtained by mixing blue and yellow. The purple color was identified as a mixture of red and blue, which also agrees with the information in Groom's manual, since there is no purple pigment mentioned; indeed, other authors refer the mixture of red and blue to achieve the purple color.

By means of infrared analyses, it was possible to identify a complex matrix where the presence of a terpenoid resin such as shellac was detected. This resin could have been used as a varnish and/or binding media; however, the presence of other binders cannot be excluded. Degradation products, such as metal carboxylates, were also detected in the paints, but fortunately, no macroscopic signs of alteration in their conservation state are presently observed.

This collection will be further investigated to deepen our understanding concerning the techniques and materials used. The paint layers will be examined in cross-section to perceive how they were actually applied. SERS and HPLC-DAD will be used to fully characterize the red and yellow organic colorants and mass spectrometry techniques will be applied to advance our knowledge on the possible binders and varnishes used.

Author Contributions: B.R. carried out the surface examination, microscopy analysis and data interpretation. Â.S. performed data acquisition and interpretation. M.J.M. acquired and interpreted infrared data. V.O. carried out data interpretation and co-supervised the preparation of the manuscript. M.V. supervised the research work and the preparation of the manuscript. B.R., Â.S., V.O., and M.V. contributed to the research of the historical written sources as well as to the writing and revision of the manuscript. All authors read and approved the final manuscript.

Funding: This research was funded by the Portuguese Foundation for Science and Technology (FCT-MCTES) through the doctoral program CORES-PD/00253/2012, the PhD grant PD/BD/136694/2018 (Ângela Santos), and the Research Units VICARTE (UID/EAT/00729/2019) and LAQV-REQUIMTE (UID/QUI/50006/2019).

Acknowledgments: This research has benefited from the use of the infrastructure PRISC (Portuguese Research Infrastructure of Scientific Collections). The authors are thankful to MUHNAC - Museum of Natural History and Science of the University of Lisbon for the collaboration in this project (Lanterna Magica - Technology and Preservation of Painted Glass Slides for Projection with Magic Lanterns).

Conflicts of Interest: The authors declare no conflict of interest.

\section{Appendix A}

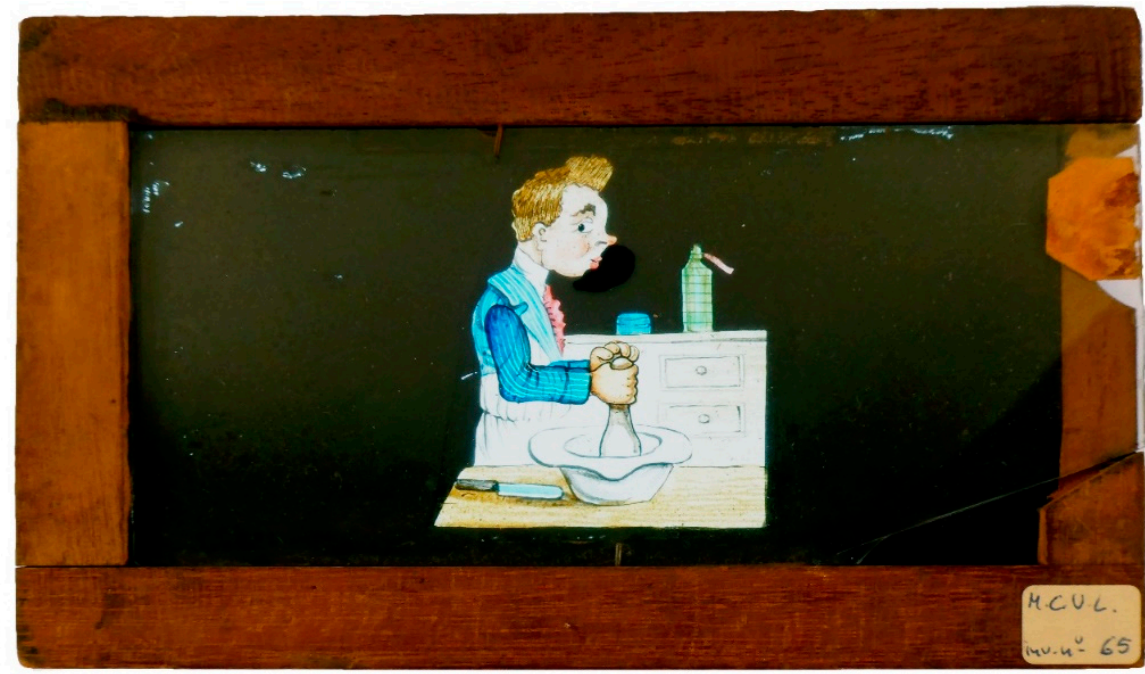

Figure A1. Hand-painted glass slide with inventory number MUL/MUHNAC UL000065 from MUHNAC-ULisboa. 


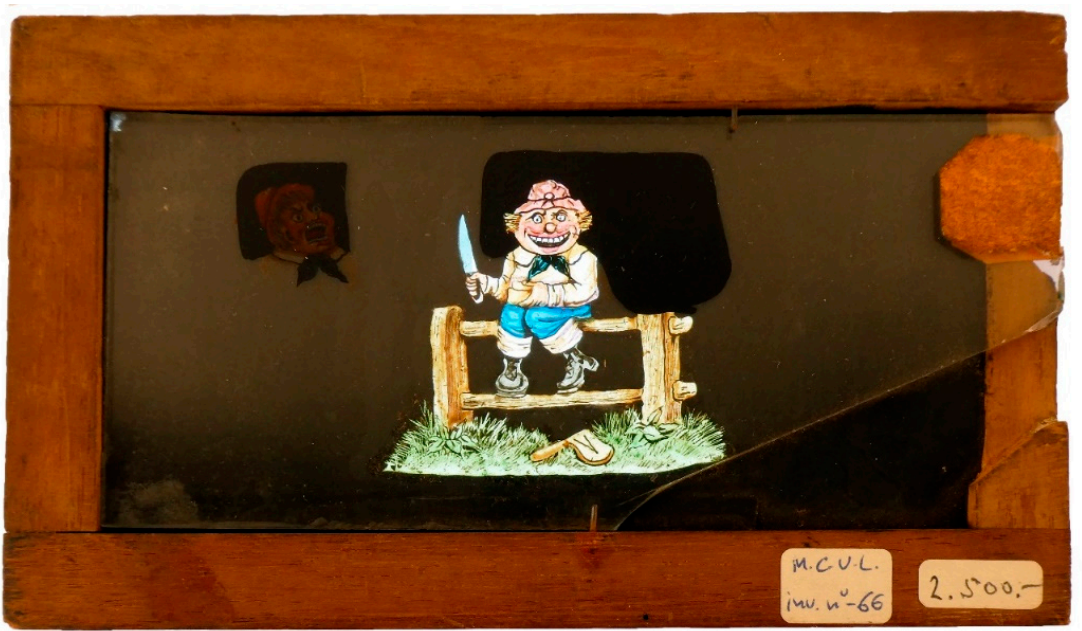

Figure A2. Hand-painted glass slide with inventory number MUL/MUHNAC UL000066 from MUHNAC-ULisboa.

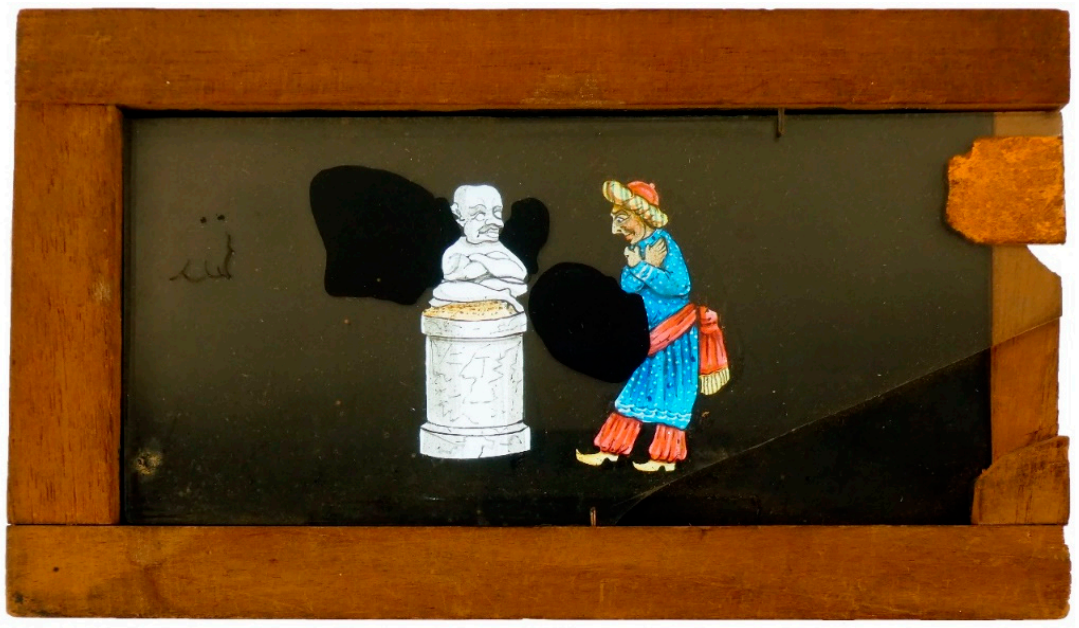

Figure A3. Hand-painted glass slide with inventory number MUL/MUHNAC UL000067 from MUHNAC-ULisboa.

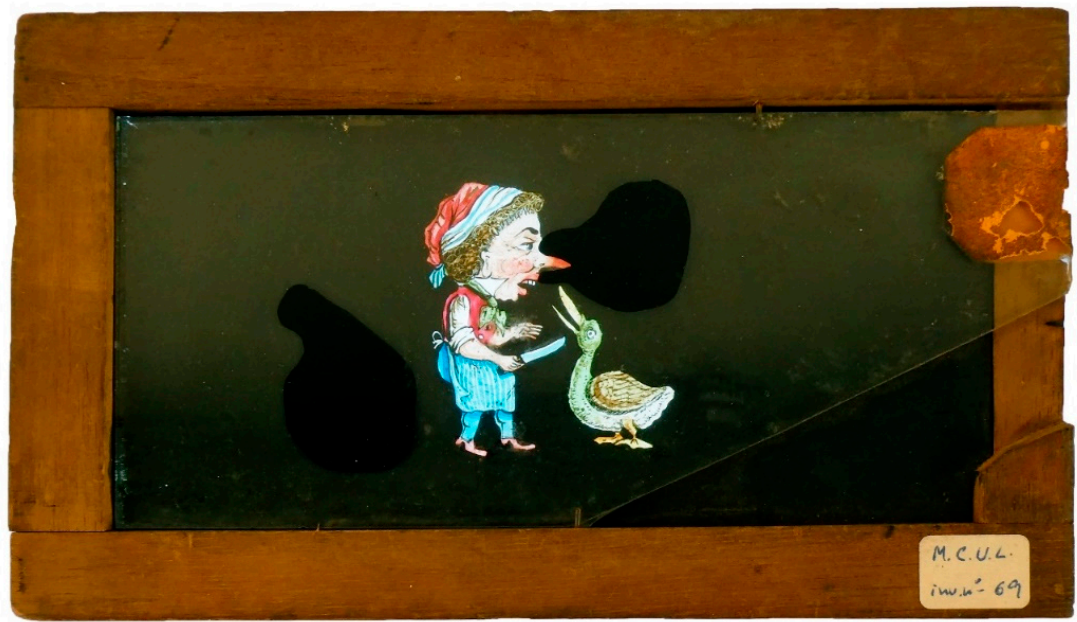

Figure A4. Hand-painted glass slide with inventory number MUL/MUHNAC UL000069 from MUHNAC-ULisboa. 


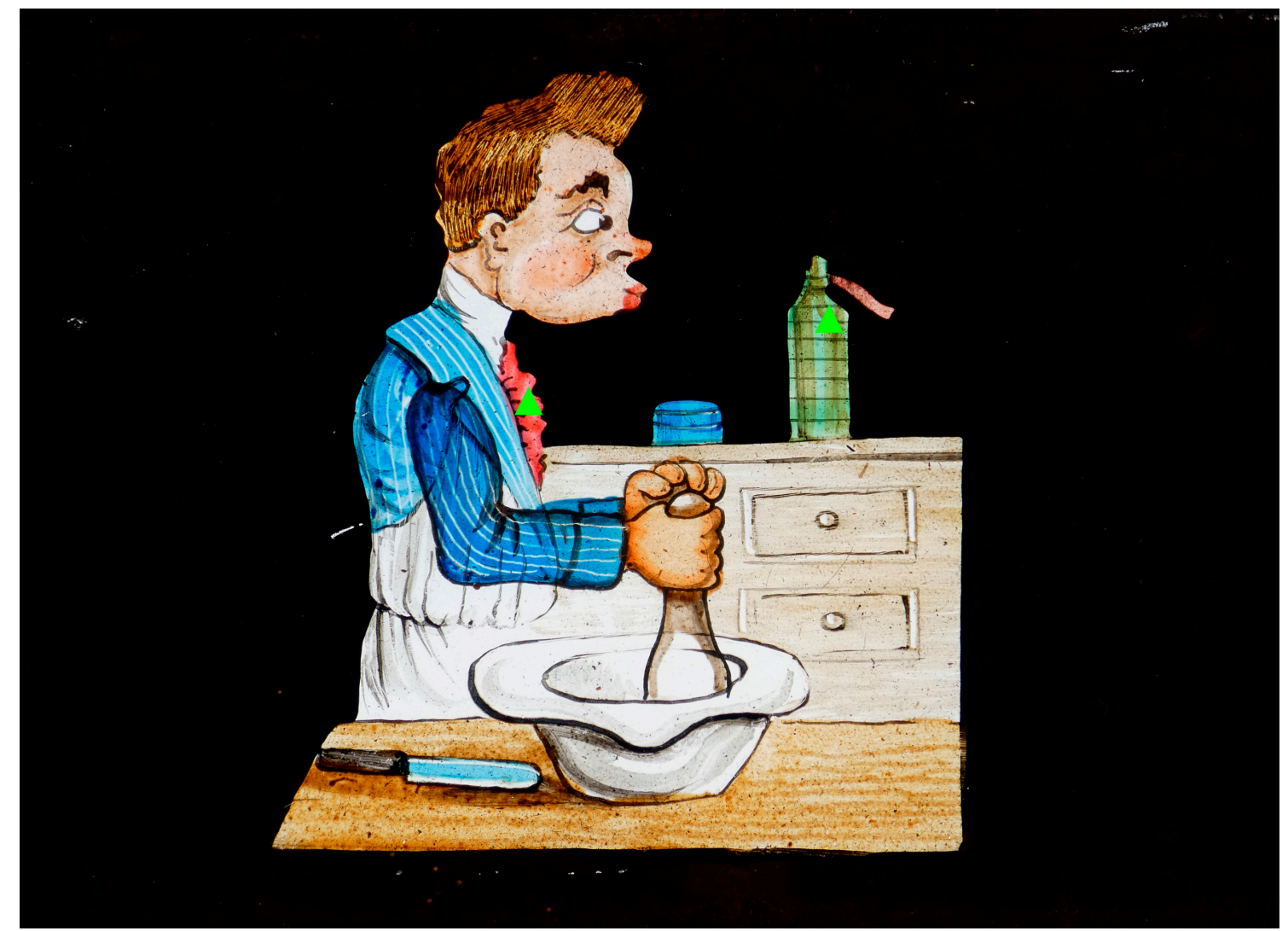

Figure A5. Mapping of the analysis performed on the slide MUL/MUHNAC UL000065. UV-Vis spectroscopy analyses $(\mathbf{\Lambda})$ : red and green paints.

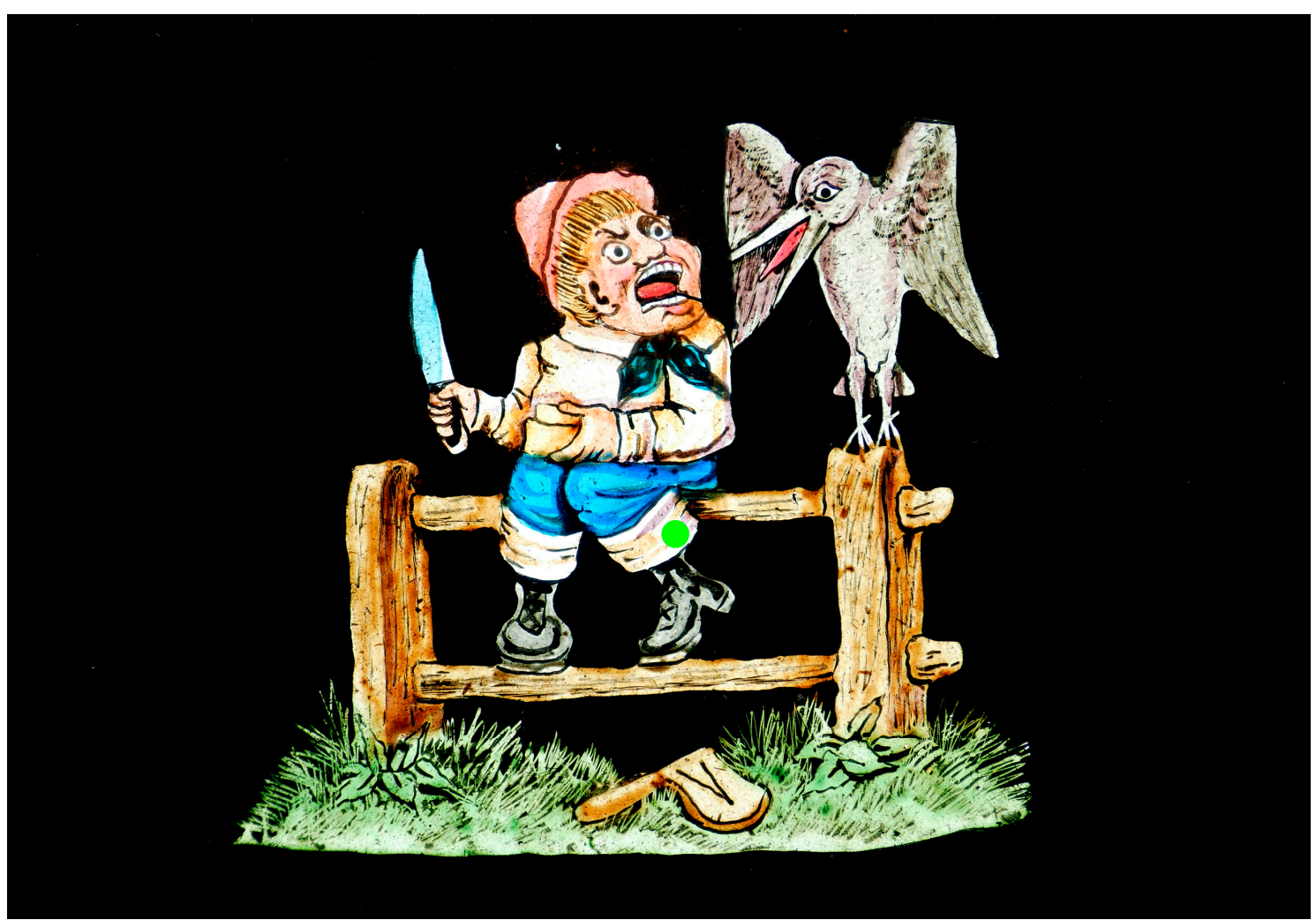

Figure A6. Mapping of the analysis performed on the slide MUL/MUHNAC UL000066. $\mu$-FTIR spectroscopy analysis $(\bullet)$ : purple paint. 


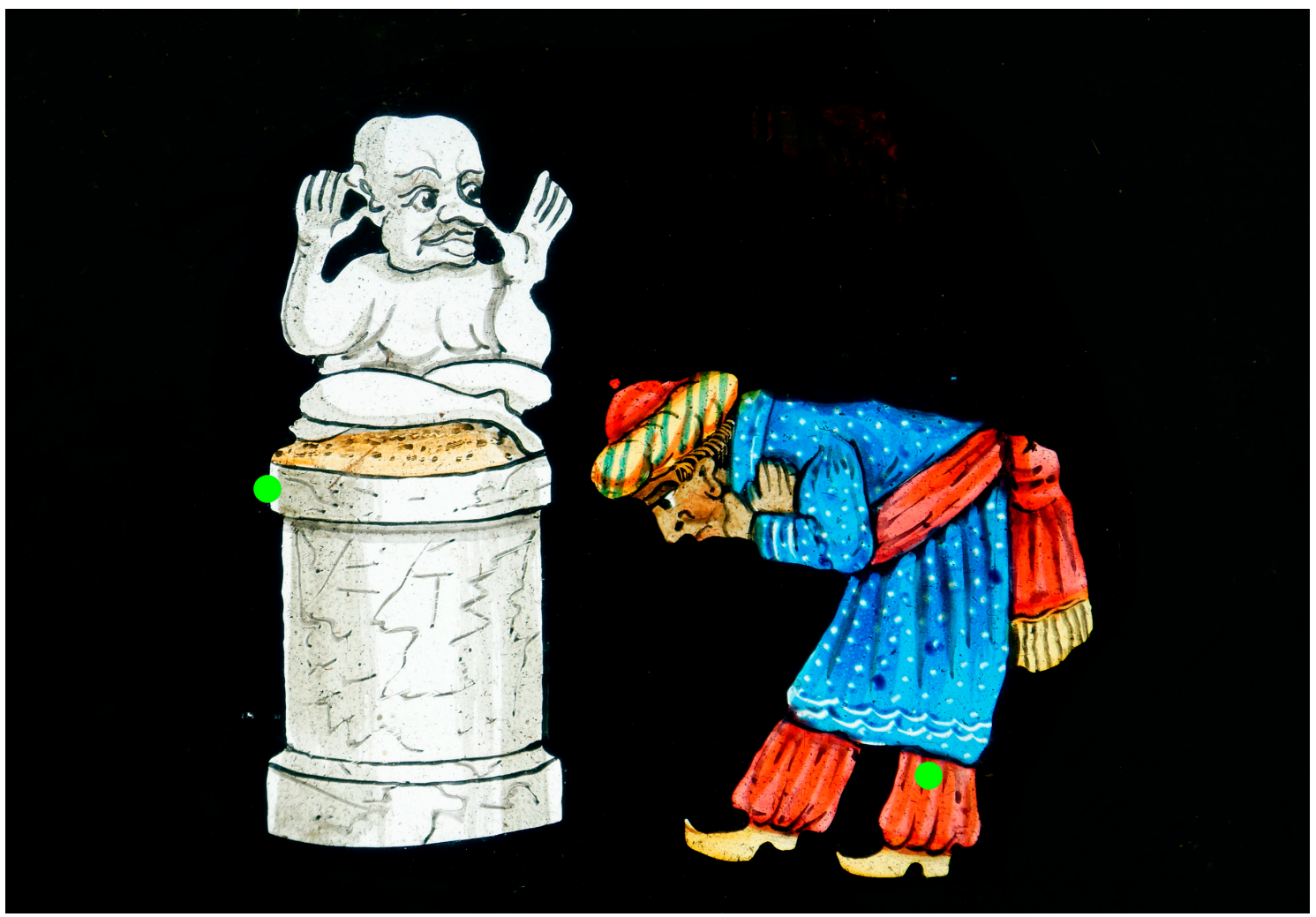

Figure A7. Mapping of the analysis performed on the slide MUL/MUHNAC UL000067. $\mu$-FTIR spectroscopy analyses $(\bullet)$ : drop of varnish and red paint.

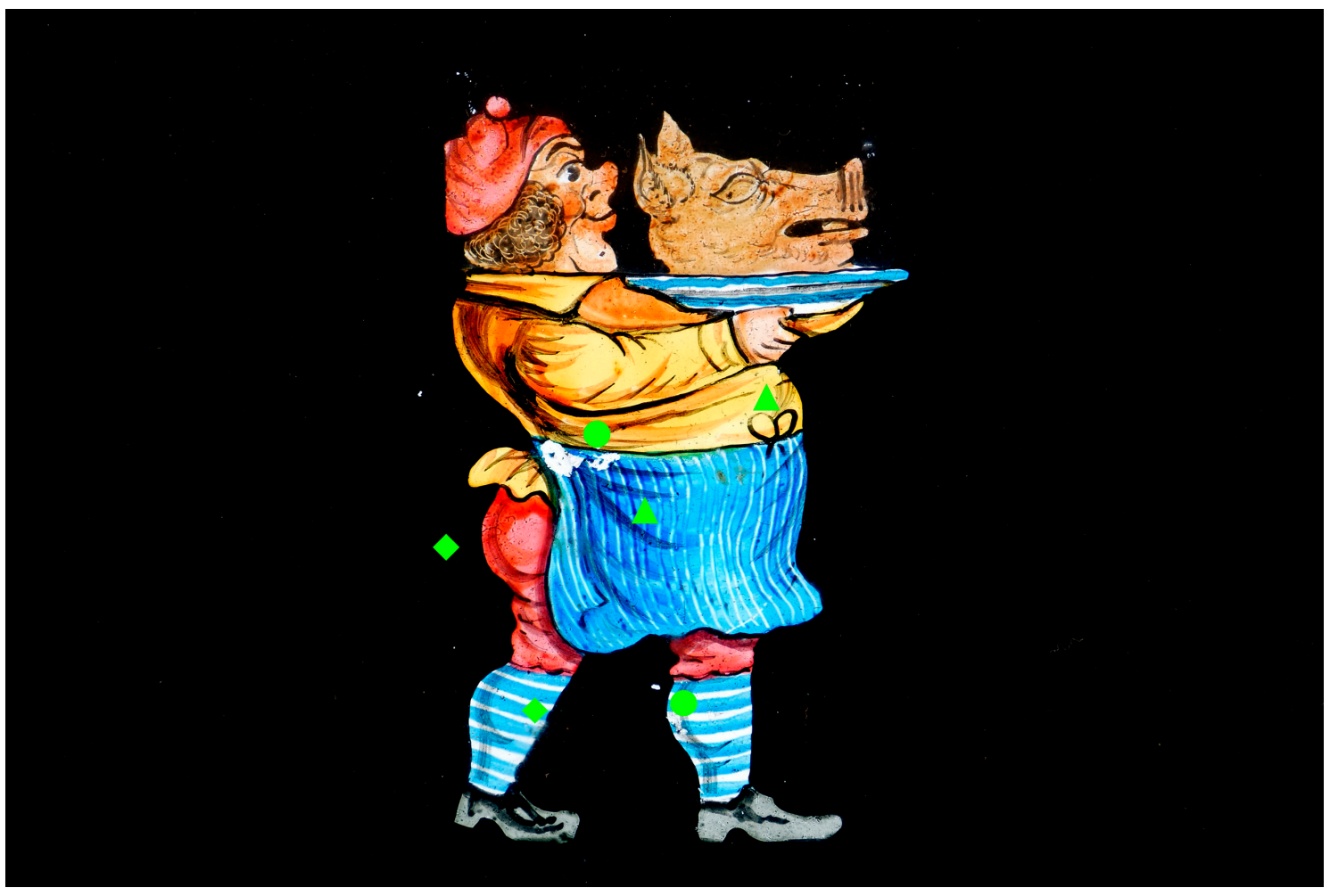

Figure A8. Mapping of the analysis performed to the slide MUL/MUHNAC UL000066. UV-Vis spectroscopy analyses $(\boldsymbol{\Lambda})$ : blue and yellow paints; $\mu$-FTIR spectroscopy analyses $(\bullet)$ : blue and yellow paints; and $\mu$-Raman spectroscopy analysis $(\bullet)$ : blue paint. 


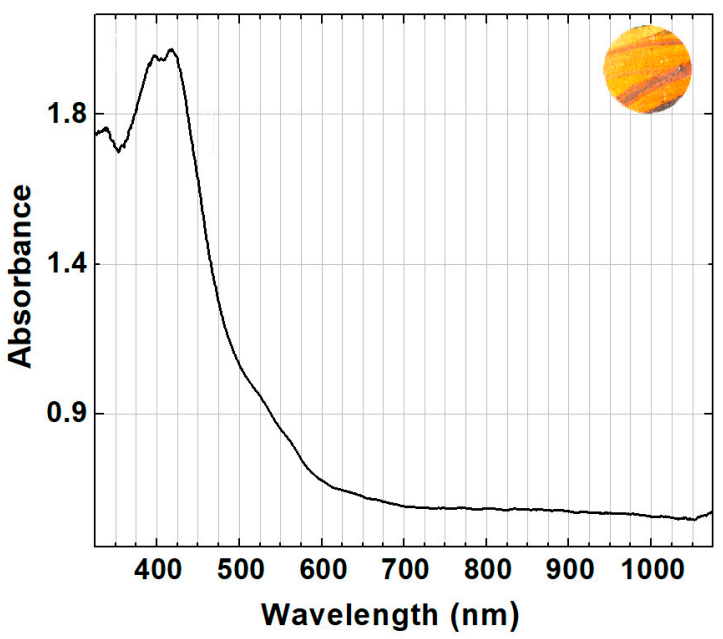

Figure A9. UV-Vis spectrum of the yellow color, not yet identified.

\section{References}

1. Frutos, F.J. Un público encantado. Las proyecciones audiovisuales mediante linterna mágica al servicio de la divulgación científica. Cult. Educ. 2009, 21, 305-318. [CrossRef]

2. Balzer, R. Optical Amusements: Magic Lanterns and Other Transforming Images. A Catalog of Popular Entertainments; Museum of Our National Heritage: Watertown, MA, USA, 1987.

3. Frutos, F.J. From Luminous Pictures to Transparent Photographs: The Evolution of Techniques for Making Magic Lantern Slides. Magic Lantern Gaz. 2013, 25, 3-11.

4. Magic Lantern Slide Show; Tasmanian School of Art Gallery: Hobart, Australia, 1979.

5. Campagnoni, D.P.; Bartetto, P. História da Lanterna Megalográphica vulgarmente dita Lanterna Mágica. In A Magia da Imagem-A Arqueologia do Cinema do Museu Nacional do Cinema de Turim; Cinemateca Portuguesa, Centro Cultural de Belém: Lisboa, Portugal, 1996.

6. Heard, M. The lantern is not dead: Lanterns and slides in the 20th century and beyond. In Realms of Light: Uses and Perceptions of the Magic Lantern from the 17th to the 21st Century, Crangle, R., Heard, M., van Dooren, I., Eds.; Magic Lantern Society: London, UK, 2005; pp. 193-194.

7. Mannoni, L.; Campagnoni, D.P. Lanterne Magique et Film Peint: 400 ans de Cinéma; Cinémathèque Française: Paris, France, 2009.

8. Gray, F. Engaging with the Magic Lantern's History. In Screen Culture and the Social Question, 1880-1914; Crangle, R., Vogl-Bienek, L., Eds.; Indiana University Press, John Libbey Publishing: Bloomington, IN, USA, 2014; pp. 173-181.

9. Vogl-Bienek, L. Lichtspiele im Schatten der Armut: Historische Projektionskunst und Soziale Frage; Stroemfeld Verlag: Frankfurt, Germany, 2016.

10. Scalarone, D.; Agostino, A.; Chiantore, O.; Basano, R. Vetri da proiezione dipinti per lanterne magiche: Analisi non invasive di leganti e pigmenti. In Proceedings of the IV Congresso Nazionale IGIIC-Lo Stato dell'Arte, Sienna, Italy, 28-30 September 2006.

11. Ploeger, R.; Scalarone, D.; Chiantore, O. Non-invasive characterisation of binding media on painted glass magic lantern plates using mid-infrared fibre-optic reflectance spectroscopy. J. Cult. Herit. 2010, 11, 35-41. [CrossRef]

12. Groom, E. The Art of Transparent Painting on Glass; Winsor \& Newton: London, UK, 1855.

13. Directions for the Graduation and Mixture of Colors, to Which Are Added Directions for Transparent Painting on Glass; M. J. Whipple \& Co.: Boston, MA, USA, 1856.

14. Hepworth, T.C. The Book of the Lantern. Being a Practical Guide to the Working of the Optical (or Magic) Lantern; Wyman \& Sons: London, UK, 1888.

15. Middleton, C. Magic Lantern Dissolving View Painting; Brodie \& Middleton: London, UK, 1876.

16. Hughes, W.C. The Art of Projection and Complete Magic Lantern Manual; E. A. Beckett: London, UK, 1893.

17. Rintoul, A.N. Transparent Painting on Glass for the Magic Lantern, in Water, Oil, \& Varnish colors; Brodie \& Middleton: London, UK, 1867. 
18. Chadwick, W.I. The Magic Lantern Manual; Scovill Manufacturing Company: New York, NY, USA, 1886.

19. Crompton, D.; Henry, D.; Herbert, S. Magic Images: The art of Hand-Painted and Photographic Lantern Slides; The Magic Lantern Society of Great Britain: London, UK, 1990.

20. Brill, R.H. Chemical Analyses of Early Glasses. Volume 2: Tables of Analyses; The Corning Museum of Glass: New York, NY, USA, 1999; p. 544.

21. Dungworth, D. Historic Window Glass. J. Archit. Conserv. 2012, 18, 7-25. [CrossRef]

22. Boselli, L. Non-Invasive Spectroscopic Study of 19th Century Artists' Materials. Ph.D. Thesis, Università degli Studi di Ferrara, Ferrara, Italy, 2010.

23. Bacci, M.; Magrini, D.; Picollo, M.; Vervat, M. A study of the blue colors used by Telemaco Signorini (1835-1901). J. Cult. Herit. 2009, 10, 275-280. [CrossRef]

24. Moretti, G.; Gervais, C. Raman spectroscopy of the photosensitive pigment Prussian blue. J. Raman Spectrosc. 2018, 49, 1198-1204. [CrossRef]

25. Aceto, M.; Agostino, A.; Fenoglio, G.; Idone, A.; Gulmini, M.; Picollo, M.; Ricciardi, P.; Delaney, J.K. Characterisation of colourants on illuminated manuscripts by portable fibre optic UV-visible-NIR reflectance spectrophotometry. Anal. Methods 2014, 6, 1488-1500. [CrossRef]

26. Vitorino, T.; Casini, A.; Cucci, C.; Melo, M.J.; Picollo, M.; Stefani, L. Non-invasive identification of traditional red lake pigments in fourteenth to sixteenth centuries paintings through the use of hyperspectral imaging technique. Appl. Phys. A Mater. Sci. Process. 2015, 121, 891-901. [CrossRef]

27. Vitorino, T.; Otero, V.; Carlyle, L.; Melo, M.J.; Parola, A.J.; Picollo, M. Nineteenth-century cochineal lake pigments from Winsor \& Newton: Insight into their methodology through reconstructions. In Proceedings of the ICOM-CC 18th Triennial Conference, Copenhagen, Denmark, 4-8 September 2017.

28. Vitorino, T. Red Lake Pigments: From the Study of Their Chromophores and Historically Accurate References to a Comprehensive Hyperspectral Imaging Database. Ph.D. Thesis, Universidade Nova de Lisboa, Lisbon, Portugal, forthcoming.

29. Bell, I.M.; Clark, R.H.; Gibbs, P.J. Raman spectroscopic library of natural and synthetic pigments (pre- 1850 AD). Spectrochim. Acta Part A Mol. Biomol. Spectrosc. 1997, 53, 2159-2179. [CrossRef]

30. Tomasini, E.P.; Halac, E.B.; Reinoso, M.; Di Liscia, E.J.; Maier, M.S. Micro-Raman spectroscopy of carbon-based black pigments. J. Raman Spectrosc. 2012, 43, 1671-1675. [CrossRef]

31. Vetter, W.; Schreiner, M. Characterization of pigment-binding media systems comparison of non-invasive in-situ reflection FTIR with Transmission FTIR Microscopy. e-Preserv. Sci. 2011, 8, 10-22.

32. Montagner, C.; Sanches, D.; Pedroso, J.; Melo, M.J.; Vilarigues, M. Ochres and earths: Matrix and chromophores characterization of 19 th and 20th century artist materials. Spectrochim. Acta Part A Mol. Biomol. Spectrosc. 2013, 103, 409-416. [CrossRef] [PubMed]

33. Sarkar, P.C.; Shrivastava, A.K. FTIR spectroscopy of lac resin and its derivatives FTIR spectroscopy of lac resin and its derivatives. Pigment Resin Technol. 1997, 26, 370-377. [CrossRef]

34. Ortega-Avilés, M.; Vandenabeele, P.; Tenorio, D.; Murillo, G.; Jiménez-Reyes, M.; Gutiérrez, N. Spectroscopic investigation of a 'Virgin of Sorrows' canvas painting: A multi-method approach. Anal. Chim. Acta 2005, 550, 164-172. [CrossRef]

35. Tamburini, D.; Dyer, J.; Bonaduce, I. The characterisation of shellac resin by flow injection and liquid chromatography coupled with electrospray ionisation and mass spectrometry. Sci. Rep. 2017, 7, 14784. [CrossRef] [PubMed]

36. Sutherland, K. Bleached shellac picture varnishes: Characterization and case studies. J. Inst. Conserv. 2010, 33, 129-145. [CrossRef]

37. Carlyle, L. The Artist's Assistant: Oil Painting Instruction Manuals and Handbooks. In Britain 1800-1900 with Reference to Selected Eighteenth-Century Sources; Archetype Publications: London, UK, 2001.

38. Otero, V.; Sanches, D.; Montagner, C.; Vilarigues, M.; Carlyle, L.; Lopes, J.A.; Melo, M.J. Characterisation of metal carboxylates by Raman and infrared spectroscopy in works of art. J. Raman Spectrosc. 2014, 45, 1197-1206. [CrossRef]

39. Monico, L.; Rosi, F.; Miliani, C.; Daveri, A.; Brunetti, B.G. Non-invasive identification of metal-oxalate complexes on polychrome artwork surfaces by reflection mid-infrared spectroscopy. Spectrochim. Acta Part A Mol. Biomol. Spectrosc. 2013, 116, 270-280. [CrossRef]

40. Poli, T.; Piccirillo, A.; Zoccali, A.; Conti, C.; Nervo, M.; Chiantore, O. The role of zinc white pigment on the degradation of shellac resin in artworks. Polym. Degrad. Stab. 2014, 102, 138-144. [CrossRef] 
41. Doménech-Carbó, M.T.; Kuckova, S.; de la Cruz-Cañizares, J.; Osete-Cortina, L. Study of the influencing effect of pigments on the photoageing of terpenoid resins used as pictorial media. J. Chromatogr. A 2006, 1121, 248-258. [CrossRef]

42. Poli, T.; Piccirillo, A.; Nervo, M.; Chiantore, O. Interactions of natural resins and pigments in works of art. J. Colloid Interface Sci. 2017, 503, 1-9. [CrossRef] [PubMed]

(C) 2019 by the authors. Licensee MDPI, Basel, Switzerland. This article is an open access article distributed under the terms and conditions of the Creative Commons Attribution (CC BY) license (http://creativecommons.org/licenses/by/4.0/). 